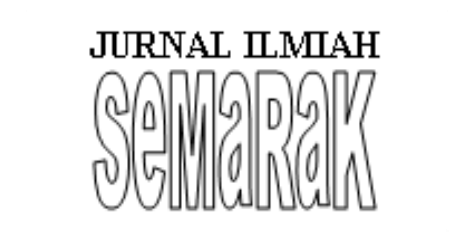

P-ISSN 2615-6849, E-ISSN 2622-3686

Jurnal Semarak,Vol.4,No.1,Februari 2021, Hal (80-95)

@Prodi Manajemen Fakultas Ekonomi Universitas Pamulang

\title{
ANALISIS PENGARUH ARUS KAS, MODAL KERJA BERSIH, HUTANG JANGKA PENDEK TERHADAP LABA DAN DAMPAKNYA TERHADAP PEMBAGIAN DIVIDEN
}

\author{
Ayu Puspa Lestiyadi \\ Dosen Ekonomi Universitas PamuIang \\ EmaiI : dosen02505@unpam.ac.id
}

\begin{abstract}
Penelitian ini bertujuan untuk mengetahui pengaruh arus kas, modal kerja bersih, hutang jangka pendek terhadap laba dan dampaknya terhadap pembagian dividen (studi pada perusahaan industri makanan dan minuman yang terdaftar di bursa efek indonesia (BEI) tahun 2011-2016.

Penelitian ini menggunakan metode penelitian deskriptif kuantitatif dan mengambil data secara time series berupa laporan keuangan periode 20011-2016. Sumber data yang diperoleh dari situs Bursa Efek Indonesia (Internet Data Exchange/IDX). Metode penentuan sampel dengan metode purposive sampling, sehingga didapatkan sampel sebanyak 6 perusahaan industri makanan dan minuman. Analisis data dilakukan dengan uji asumsi klasik dan pengujian hipotesis dengan metode regresi berganda dengan alat bantu aplikasi Eviews Versi 9.0.

Hasil uji hipotesis dari penelitian ini adalah sebagai berikut: arus kasterhadap laba pada uji parsial diperoleh nilai $t_{\text {hitung }}>t_{\text {tabel }}(2.515>1.694)$, yang berarti menunjukan bahwa variabel arus kas berpengaruh secara signifikan terhadap laba. Modal kerja bersih terhadap laba pada uji parsial diperoleh nilai $t_{\text {hitung }}>t_{\text {tabel }}(13.565>1.694)$, yang berarti menunjukan bahwa variabel modal kerja bersih berpengaruh signifikan terhadap laba. Hutang jangka pendek terhadap laba pada uji parsial diperoleh nilai $t_{\text {hitung }}>t_{\text {tabel }}(9.889>1.694)$, yang berarti menunjukan bahwa variabel hutang jangka pendek berpengaruh signifikan terhadap laba. Hasil uji simultan pengaruh arus kas, modal kerja bersih, dan hutang jangka pendek terhadap laba diperoleh nilai $F_{\text {hitung }}>F_{\text {tabel }} \quad(85.124>$ 2.90), yang berarti menunjukan bahwa arus kas, modal kerja bersih dan hutang jangka pendek secara simultan berpengaruh terhadap laba. Sedangkan hasil uji laba terhadap pembagian dividen diperoleh hasil $t_{\text {hitung }}>t_{\text {tabel }}(9.793>1.694)$, yang berarti bahwa variabel laba secara parsial berpengaruh terhadap pembagian dividen.
\end{abstract}

Kata kunci :Arus Kas, Modal Kerja Bersih, Hutang Jangka Pendek, Laba dan Dividen 
JRNAL ПMПAH

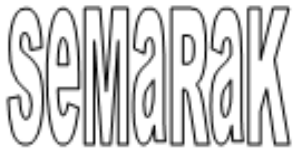

P-ISSN 2615-6849, E-ISSN 2622-3686

Jurnal Semarak,Vol.4,No.1,Februari 2021, Hal (80-95)

@Prodi Manajemen Fakultas Ekonomi Universitas Pamulang

\begin{abstract}
This study aims to determine the effect of cash flow, net working capital, short-term debt to earnings and its impact on the dividend distribution (study on food and beverage industry companies listed on the stock exchange Indonesia (BEI) in 2011-2016.

This research uses quantitative descriptive research method and retrieve data in time series in the form of financial statements period 20011-2016. Source of data obtained from Indonesia Stock Exchange (IDX) website. The method of determining the sample by purposive sampling method, so that got samples of 6 companies of food and beverage industry. Data analysis was done with classical assumption test and hypothesis testing with multiple regression method with Eviews Version 9.0 application tool.

Hypothesis test result from this research is as follows: cash flow to profit on partial test obtained value $t_{\text {count }}>t_{\text {table }}(2.515>1.694)$, which means show that variable cash flow effect significantly to earnings. Net working capital to profit on the partial test obtained value $t_{\text {count }}>t_{\text {table }}(13,565>$ 1,694), which means show that net working capital variables significantly affect earnings. Shortterm debt to profit on the partial test obtained value $t_{\text {count }}>t_{\text {table }}(9.889>1.694)$, which means that the variable of short-term debt significantly affects earnings. The simultaneous test result of the influence of cash flow, net working capital, and short-term debt to earnings obtained value $F_{\text {count }}>F_{\text {table }}(85.124>2.90)$, which means that cash flow, net working capital and short-term debt simultaneously affect earnings. While the result of profit test to dividend division obtained result $t_{\text {count }}>t_{\text {table }}(9.793>1.694)$, which means that variable earnings partially influence to dividend distribution.
\end{abstract}

Keywords: Cash Flow, Net Working Capital, Short Term Debt, Profit and Dividend 
JRNAL IMாAH Sammandad
P-ISSN 2615-6849, E-ISSN 2622-3686

Jurnal Semarak,Vol.4,No.1,Februari 2021, Hal (80-95)

@Prodi Manajemen Fakultas Ekonomi Universitas Pamulang

\section{PENDAHULUAN}

\section{A. Latar BeIakang MasaIah}

Dalam menjalankan usahanya, setiap perusahaan selalu membutuhkan kas. kas diperlukan baik untuk membiayai operasi perusahaan setiap hari maupun untuk melakukan investasi baru dalam aktiva tetap.

Keberhasilan perusahaan dalam mempertahankan kelangsungan usahanya tergantung dengan tersedianya uang tunai atau kas untuk membayar kewajibankewajiban finansial dalam waktu yang segera dan tepat waktu, seperti untuk pembelian bahan mentah, pembayaran upah buruh dan gaji, pembayaran listrik, air, telepon, dan lain-lain.

Selain kas, Perusahaan yang sedang berkembang memerlukan modal untuk menjalankan keputusan dalam melakukan investasi. Modal tersebut dapat diperoleh dari keuntungan maupun ekuitas. Hal tersebut menimbulkan suatu keputusan penting yang harus diambil dari seorang manajer keuangan yaitu keputusan dalam memperoleh modal untuk memenuhi kebutuhan investasi, karena setiap sumber pendanaan yang berbeda akan mempunyai implikasi yang berbeda pula pada perusahaan. Dari pendanaan yang diperoleh tersebut akan digunakan perusahaan untuk membiayai investasi sehingga perusahaan dapat memperoleh keuntungan atas pendanaa asset yang dilakukan. Modal senantiasa menjadi persoalan mendasar bagi dunia bisnis, terutama didalam menghadapi persaingan di era globalisasi. Tersedianya modal merupakan kebutuhan mutlak yang harus dipenuhi, jika tidak tersedia modal, sulit untuk mengembangkan kinerja usaha dan bersaing dalam pentas dunia.

Modal kerja sebaiknya tersedia dalam jumlah yang cukup agar memungkinkan perusahaan untuk beroperasi secara ekonomis dan tidak mengalami kesulitan keuangan, keputusan yang berkaitan dengan modal kerja juga harus diambil dengan hati-hati, karena jika perusahaan tidak dapat mempertahankan tingkat modal kerja dengan baik maka kemungkinan perusahaan akan berada dalam keadaan insolvent (tidak mampu membayar kewajiban-kewajiban yang sudah jatuh tempo) dan bahkan mungkin bisa bangkrut. Namun jumlah modal kerja juga harus dijaga agar tidak berlebihan sehingga terdapat dana yang menganggur yang tidak produktif.

Pada prinsipnya perusahaan dalam memenuhi kebutuhan dananya dapat berasal dari pinjaman, maka perusahaan itu dikatakan melakukan hutang atau pembelanjaan hutang (debt financing) dimana hutang tersebut dapat dikatakan hutang jangka pendek dan hutang jangka panjang. Hutang jangka pendek menitikberatkan pada kemampuan perusahaan dalam memenuhi kewajiban jangka pendeknya, sedangkan hutang jangka panjang menitikberatkan pada kondisi keuangan jangka panjang, laba sekarang dan laba yang akan datang. Untuk melaksanakan fungsi pemenuhan kebutuhan dana, manajer keuangan harus selalu mencari alternatif-alternatif sumber dana dan diambil keputusan alternatif sumber dana mana yang akan dipilih. Selain dalam melakukan pemanfaatan dana, manajemen juga harus mampu memanfaatkan dengan maksimal seluruh potensi yang ada dalam perusahaan, salah satu faktor yang harus diperhatikan dan dimaksimumkan pemanfaatannya adalah modal kerja.

Ukuran yang seringkali digunakan untuk menentukan sukses tidaknya manajemen perusahaan adalah laba yang diperoleh perusahaan. Pengukuran laba bukan saja penting untuk menentukan prestasi perusahaan, tetapi juga penting sebagai informasi bagi pembagian laba dan 
JRNAL IMாAH

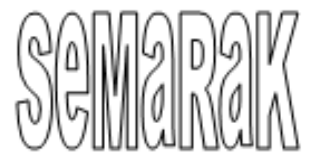

P-ISSN 2615-6849, E-ISSN 2622-3686

Jurnal Semarak,Vol.4,No.1,Februari 2021, Hal (80-95)

@Prodi Manajemen Fakultas Ekonomi Universitas Pamulang penentuan kebijakan investasi. Laba atau rugi sering dimanfaatkan sebagi ukuran untuk menilai prestasi perusahaan atau sebagai dasar penilaian yang lain, seperti laba perlembar saham. Unsur-unsur yang menjadi bagian pembentuk laba adalah pendapatan dan biaya. Dengan mengelompokkan unsur-unsur pendapatan dan biaya, akan diperoleh hasil pengukuran laba yang berbeda antara lain laba kotor, laba operasi, laba sebelum pajak dan laba bersih.

Perusahaan yang memiliki tingkat akumulasi laba bersih yang cukup baik dari satu periode ke periode berikutnya, biasanya memiliki potensi untuk dapat membagikan sebagian dari laba bersih tersebut kepada pemilik perusahaan (pemegang saham dalam bentuk dividend). Pada umumnya, investor menginvestasikan dananya untuk membeli saham dengan tujuan agar memperoleh return dalam bentuk capital gain atau dividen. Capital gain terjadi dikarenakan adanya mekanisme pasar atas transaksi jual beli saham, sedangkan deviden murni berasal dari perusahaan.

Enam perusahaan industri di bidang makanan dan minuman yang di maksud dalam penelitian ini yang masih beroperasi secara baik dan lancar antara lain PT. Sekar Laut Tbk, PT. Indofood CBP Sukses Makmur Tbk, PT. Indofood Sukses Makmur, PT. Delta Djakarta Tbk, PT. Mayora Indah Tbk, dan PT. Nippon Indosari Corpindo Tbk, hingga saat ini masih dapat mempertahankan kontinuitas perusahaan. Salah satu faktor keberhasilan tersebut adalah pengelolaan hutang jangka panjang dan jangka pendek serta modal kerja yang baik dan efisien. Jika kontinuitas perusahaan terus berjalan dan keuntungan perusahaan pada setiap penjualan produk mampu dipertahankan akan berdampak tidak adanya penambahan modal kerja untuk kegiatan operasional.
Berikut tabel laporan arus kas, modal kerja bersih, hutang jangka pendek, dan laba perusahaan manufaktur bidang makanan dan minuman, tahun 2011 sampai dengan 2016 yang digunakan dalam penelitian ini.

Tabel Laporan Arus Kas, Modal Kerja

Bersih, Hutang Jangka Pendek, Laba dan Dividen Perusahaan Industri Makanan dan Minuman yang Terdaftar Di BEI Tahun 2011-2016

\section{( Dalam Jutaan Rupiah)}

\begin{tabular}{|c|c|c|c|c|c|c|}
\hline No & \begin{tabular}{|c|} 
Nama \\
Perusahaan \\
$/$ Tahun
\end{tabular} & Arus Kas & $\begin{array}{l}\text { Modal } \\
\text { Kerja } \\
\text { Bersih } \\
\end{array}$ & $\begin{array}{l}\text { Hutang } \\
\text { Jangka } \\
\text { Pendek } \\
\end{array}$ & Laba & Dividen \\
\hline \multirow[t]{7}{*}{1} & $\begin{array}{l}\text { PT. Sekar } \\
\text { Laut Tbk }\end{array}$ & & & & & \\
\hline & 2011 & 4.156 & 43.201 & 61.944 & 5.977 & 1.381 \\
\hline & 2012 & $(12.000)$ & 36.842 & 88.825 & 7.963 & 1.381 \\
\hline & 2013 & $(8.776)$ & 29.396 & 125.712 & 11.440 & 2.072 \\
\hline & 2014 & $(14.268)$ & 25.994 & 141.425 & 16.481 & 2.763 \\
\hline & 2015 & (5.154) & 30.626 & 159.133 & 20.067 & 3.454 \\
\hline & 2016 & $(9.834)$ & 53.384 & 169.303 & 20.646 & 4.144 \\
\hline \multirow[t]{7}{*}{2} & $\begin{array}{l}\text { PT. Indofood } \\
\text { CBP Sukses } \\
\text { Makmur Tbk }\end{array}$ & & & & & \\
\hline & 2011 & 1.078 .216 & 5.591 .771 & 2.988 .540 & \begin{tabular}{|l|}
2.066 .365 \\
\end{tabular} & 149.451 \\
\hline & 2012 & 981.129 & 6.308 .953 & 3.579 .487 & \begin{tabular}{|l|l|}
2.282 .371 \\
\end{tabular} & 253.664 \\
\hline & 2013 & 16.913 & 6.625 .132 & 4.696 .583 & 2.233 .291 & 346.728 \\
\hline & 2014 & 1.847 .114 & 7.372 .530 & 6.230 .997 & 2.531 .681 & 377.903 \\
\hline & 2015 & 317.673 & 7.959 .156 & 6.002 .344 & 2.923 .148 & 373.750 \\
\hline & 2016 & 828.505 & 9.101 .577 & 6.469 .785 & \begin{tabular}{|l|}
3.631 .301 \\
\end{tabular} & 719.228 \\
\hline \multirow[t]{7}{*}{3} & $\begin{array}{l}\text { PT. Indofood } \\
\text { Sukses } \\
\text { Makmur Tbk }\end{array}$ & & & & & \\
\hline & 2011 & \begin{tabular}{|l|}
2.652 .783 \\
\end{tabular} & 11.670 .430 & 12.831 .304 & 4.891 .673 & 816.580 \\
\hline & 2012 & 211.433 & 13.122 .428 & 13.080 .544 & 4.779.446 & 1.536 .575 \\
\hline & 2013 & 298.225 & 13.300 .786 & 19.471 .309 & \begin{tabular}{|l|}
2.824 .151 \\
\end{tabular} & 1.624 .380 \\
\hline & 2014 & 639.095 & 18.314 .050 & 22.681 .686 & 4.401 .080 & 1.624 .380 \\
\hline & 2015 & $(1.078 .394)$ & 17.709 .207 & 25.107 .538 & 3.709 .501 & 1.931 .694 \\
\hline & 2016 & 400.195 & 9.766 .002 & 19.219.441 & \begin{tabular}{|l|}
5.266 .906 \\
\end{tabular} & 1.931 .694 \\
\hline \multirow[t]{7}{*}{4} & $\begin{array}{c}\text { PT. Delta } \\
\text { Djakarta Tbk }\end{array}$ & & & & & \\
\hline & 2011 & 2.112 & 481.515 & 96.129 & 151.715 & 176.145 \\
\hline & 2012 & 44.100 & 511.414 & 119.920 & 213.421 & 184.152 \\
\hline & 2013 & 143.007 & 589.120 & 158.991 & 270.498 & 192.158 \\
\hline & 2014 & (18.615) & 663.224 & 190.952 & 288.073 & 96.079 \\
\hline & 2015 & 79.725 & 761.587 & 140.419 & 192.045 & 96.079 \\
\hline & 2016 & 163.779 & 910.292 & 137.842 & 254.509 & 96.079 \\
\hline \multirow[t]{6}{*}{5} & $\begin{array}{l}\text { PT. Mayora } \\
\text { Indah Tbk }\end{array}$ & & & & & \\
\hline & 2011 & $(147.272)$ & 2.249 .507 & 1.845 .792 & 483.486 & 99.656 \\
\hline & 2012 & 1.010 .354 & 3.389 .166 & 1.924 .434 & 744.428 & 99.656 \\
\hline & 2013 & 313.384 & 3.753 .173 & 2.676 .892 & \begin{tabular}{|l|}
1.013 .558 \\
\end{tabular} & 176.314 \\
\hline & 2014 & 1.156 .219 & 3.394 .431 & 3.114 .338 & \begin{tabular}{|l|}
409.825 \\
\end{tabular} & 205.700 \\
\hline & 2015 & 851.510 & 4.302 .852 & 3.151 .495 & 1.250 .233 & 143.095 \\
\hline
\end{tabular}

Enam perusahaan ini dapat tumbuh dan berkembang sekalipun mengalami kesulitan keuangan, hal ini tentunya tidak lepas dari pengelolaan arus kas, hutang dan 
JRNAL ПMПAH

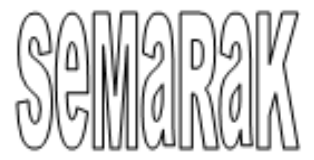

P-ISSN 2615-6849, E-ISSN 2622-3686

Jurnal Semarak,Vol.4,No.1,Februari 2021, Hal (80-95)

@Prodi Manajemen Fakultas Ekonomi Universitas Pamulang modal kerja yang dimiliki sehingga menimbulkan dampak yang baik terhadap pembagian dividen. industri makanan dan minuman yang terdaftar di Bursa Efek Indonesia (BEI)?
Dari uraian diatas, maka penulis sangat tertarik untuk meneliti "ANALISIS PENGARUH ARUS KAS, MODAL KERJA BERSIH, HUTANG JANGKA PENDEK TERHADAP LABA DAN DAMPAKNYA TERHADAP PEMBAGIAN DIVIDEN PADA PERUSAHAAN INDUSTRI MAKANAN DAN MINUMAN YANG TERDAFTAR DI BURSA EFEK INDONESIA (BEI)" sebagai judul dari penulisan tesis ini.

\section{B. Rumusan MasaIah}

1. Bagaimana pengaruh antara arus kas terhadap laba pada perusahaan industri makanan dan minuman yang terdaftar di Bursa Efek Indonesia (BEI)?

2. Bagaimana pengaruh antara modal kerjabersih terhadap laba pada perusahaan industri makanan dan minuman yang terdaftar di Bursa Efek Indonesia (BEI)?

3. Bagaimana pengaruh antara hutang jangka pendek terhadap laba pada perusahaan industri makanan dan minuman yang terdaftar di Bursa Efek Indonesia (BEI)?

4. Bagaimana pengaruh arus kas, modal kerja bersih, dan hutang jangka pendek secara simultan terhadap labapada perusahaan industri makanan dan minuman yang terdaftar di Bursa Efek Indonesia (BEI)?

5. Bagaimana pengaruh laba terhadap pembagian dividen pada perusahaan

\section{KerangkaBerfikir}

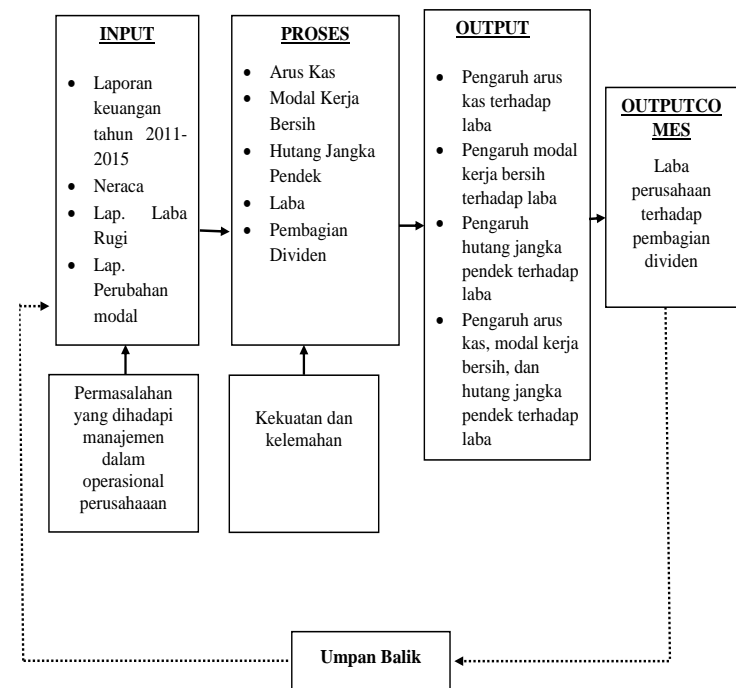

Sumber : Dikembangkan oleh peneliti, 2017

\section{Hipotesis}

1. $\mathrm{H}_{0}=$ Diduga tidak ada pengaruhnya antara arus kas terhadap laba pada perusahaan makanan dan minuman yang terdaftar di BEI $\mathrm{H}_{1}=$ Diduga ada pengaruhnya antara modal kerja bersih terhadap laba

pada perusahaan makanan dan minuman yang terdaftar di BEI

2. $\mathrm{H}_{0}=$ Diduga tidak ada pengaruhnya antara modal kerja bersih

terhadap laba pada perusahaan makanan dan 
JRNAL ПMПAH

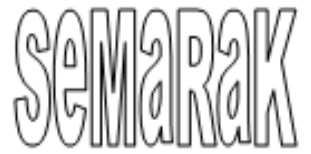

P-ISSN 2615-6849, E-ISSN 2622-3686

Jurnal Semarak,Vol.4,No.1,Februari 2021, Hal (80-95)

@Prodi Manajemen Fakultas Ekonomi Universitas Pamulang minuman yang terdaftar di BEI

$\mathrm{H}_{2}=$ Diduga ada pengaruhnya antara modal kerja bersih terhadap laba

pada perusahaan makanan dan minuman yang terdaftar di BEI

3. $\mathrm{H}_{0}=$ Diduga tidak ada pengaruhnya antara hutang jangka pendek

terhadap laba pada perusahaan makanan dan minuman yang terdaftar di BEI

$\mathrm{H}_{3}=$ Diduga ada pengaruhnya antara hutang jangka pendek terhadap

laba pada perusahaan makanan dan minuman yang terdaftar di BEI

4. $\mathrm{H}_{0}=$ Diduga tidak ada pengaruhnya antara arus kas, modal kerja bersih dan hutang jangka pendek terhadap laba pada perusahaan makanan dan minuman yang terdaftar di BEI

$\mathrm{H}_{4}=$ Diduga ada pengaruhnya antara arus kas, modal kerja bersih dan

hutang jangka pendek
terhadap laba pada
perusahaan makanan dan
minuman yang terdaftar di
BEI

5. $\mathrm{H}_{0}=$ Diduga tidak ada pengaruhnya antara laba pembagian dividen pada perusahaan makanan dan minuman yang terdaftar di BEI $\mathrm{H}_{5}=$ Diduga ada pengaruhnya antara laba terhadap dividen pada perusahaan makanan dan minuman yang terdaftar di BEI

\section{TINJAUAN PUSTAKA}

\section{A. Pengertian Kas}

Menurut Musthafa (2017:25), “Kas merupakan adalah satu unsur modal kerja yang paling tinggi tingkat likuiditasnya. Kas adalah berupa uang tunai yang terdapat dalam perusahaan dan surat berharga lainnya, serta uang yang berada di bank dalam bentuk rekening koran dan deposito atau tabungan yang dalam jangka pendek dapat diuangkan sebagai alat pembayaran.”

\section{B. Pengertian Modal kerja Bersih}

Menurut Jumingan (2011:66), modal kerja adalah kelebihan aktiva lancar terhadap hutang jangka pendek. Kelebihan ini disebut modal kerja bersih (net working capital). Kelebihan ini merupakan jumlah aktiva lancar yang berasal dari utang jangka panjang dan modal kerja sendiri.

\section{Pengertian Hutang Jangka Pendek}

Dalam pengertian lain menurut Kieso dkk (disandur dalam jurnal penelitian ekonomi dan akuntansi, Yunni, 2016:114), hutang jangka pendek ialah "the obligations that are reasonably expected to be liquidated either through the use of current assest or the creation of other currentliabilities". Surat hutang yang dengan suatu alasan pelunasannya diharapkan memlalui penggunaan dari aktiva lancar atau pengadaan dari tanggung jawab jangka pendek lainnya.

\section{Pengertian Laba}

Menurut Sri dkk dalam jurnal akuntansi dan pajak (2015:115) :

"laba merupakan kenaikan manfaat ekonomi selama satu periode akuntansi dalam bentuk pemasukan, perubahan 
JRNAL IMாAH Semlanded
P-ISSN 2615-6849, E-ISSN 2622-3686

Jurnal Semarak,Vol.4,No.1,Februari 2021, Hal (80-95)

@Prodi Manajemen Fakultas Ekonomi Universitas Pamulang aktiva atau penurunan kewajiban yang menyebabkan kenaikan ekuitas yang tidak berasal dari kontribusi penambahan modal. Laba diartikan sebgai imbalan atas upaya perusahaan dalam menghasilkan barang atau jasa sehingga laba merupakan kelebihan pendapatan diatas biaya."

\section{E. Pengertian Dividen}

Menurut Black's Law Dictionary dalam buku Irham Fahmi (2012:83), Dividen adalah "the distribution of current of accumulated earning to shareholders of corporation pro rate based on the number of share owned". Dividen merupakan pembagian keuntungan yang diberikan perusahaan dan bersasal dari keuntungan yang dihasilkan perusahaan.

\section{METODOLOGI PENELITIAN}

1. Tempat Penelitian

Penelitian yang dipilih penulis adalah perusahaan industri makanan dan minuman yang sudah go public dan untuk memperoleh data dan informasi dalam penulisan tesis ini, penulis telah melakukan penelitian pada PT. Indonesian Capital Market Electronic Library di Gedung Bursa Efek Indonesia (BEI), tower 2, lantai 1 yang berlokasi di Jl. Jenderal Sudirman Kav. 52-53 Jakarta 12190.

2. Waktu Penelitian

Penelitian ini dalam bentuk laporan keuangan dari tahun 2011 sampai dengan tahun 2016. Adapun penelitian ini dilakukan secara bertahap disesuaikan dengan tingkat kebutuhan penulis, diawali dengan persiapan pendahuluan berupa penulisan proposal judul penelitian, seminar proposal judul tesis, penyempurnaan materi proposal, pembuatan instrumen penelitian, pengumpulan data, pengolahan data yang telah didapat oleh penulis dan penyusunan pelaporan hasil tesis.

\section{A. Populasi dan Sampel}

\section{Populasi}

Populasi yang digunakan penulis adalah 18 laporan keuangan perusahaan industri makanan dan minuman yang terdaftar di Bursa Efek Indonesia (BEI).

\section{Sampel}

Laporan neraca, laporan laba rugi, laporan perubahan ekuitas dan laporan arus kas pada 6 perusahaan industri makanan dan minuman yang terdaftar di bursa efek indonesia (BEI) tahun 2011 sampai tahun 2016.

\begin{tabular}{|c|c|l}
\hline N0 & KODE & \multicolumn{1}{|c}{ NAMA PERUSAHAAN } \\
\hline 1 & SKLT & PT. Sekar Laut Tbk \\
\hline 2 & ICBP & PT. Indofood CBP Sukses Makmur Tbk \\
\hline 3 & INDF & PT. Indofood Sukses Makmur Tbk \\
\hline 4 & DLTA & PT. Delta Djakarta Tbk \\
\hline 5 & MYOR & PT Mayora Indah Tbk \\
\hline 6 & ROTI & PT Nippon Indosari Corporindo Tbk \\
\end{tabular}

\section{B. Met0de AnaIi5i5 Data}

\section{Analisis Data}

a. Model Regresi Data Panel

1) Pendekatan Polling Least Square atau Common Efect Model (CEM)

Persamaan Polling Least Square ditulis sebagai berikut :

$Y_{i t}=\alpha i+\beta X_{i t}+€_{i t}$

$i=1,2, \ldots, N$

$t=1,2, \ldots$,

Dimana :

$Y_{i t}=$ Variable dependen pada unit observasi ke-i dan waktu ke- 
JRNAL ПMПAH

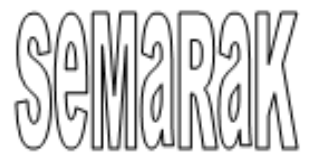

P-ISSN 2615-6849, E-ISSN 2622-3686

Jurnal Semarak,Vol.4,No.1,Februari 2021, Hal (80-95)

@Prodi Manajemen Fakultas Ekonomi Universitas Pamulang
$X_{i t}=$ Variable independen pada unit observasi ke-i dan waktu ke-t

$\alpha \quad=$ Koefisien slope atau koefisien arah

$\beta=$ Intercept model regresi

$€_{i t}=$ Komponen error pada unit observasi ke-i dan waktu ke-t

2) Pendekatan Fixed Effect Model (FEM)

Persamaan regresi pada metode ini adalah :

$$
Y_{i t}=\alpha i+\sum_{\substack{i t=2 \\ \beta X_{i t}+€_{i t}}}^{N} \alpha i D_{i t}
$$

Dimana :

$Y_{i t}=$ Variable dependen pada unit observasi ke-i dan waktu ke-t

$X_{i t}=$ Variable independen pada unit observasi ke-i dan waktu ke-t

$\alpha=$ Koefisien slope atau koefisien arah

$\beta 0 i=$ Intercept model regresi pada unit observasi ke-i

$€_{i t}=$ Komponen error pada unit observasi ke-i dan waktu ke-t

3) Pendekatan Random Effect

Persamaan model yang digunakan adalah :

$$
\begin{gathered}
\text { Yit }=\beta 0 i+\beta \text { Xit }+€ i t \\
i=1,2, \ldots, N \\
t=1,2, \ldots, N
\end{gathered}
$$

Dimana :

Yit $=$ Variable dependen pada unit observasi ke-I dan waktu ke-t
Xit $=$ Variable independen pada unit observasi ke-I dan waktu ke-t

$\beta=$ Koefisien slope atau koefisien arah

$\beta 0 \mathrm{i}=$ Intercept model regesi pada unit observasi ke-i

ui $=$ Komponen error pada unit observasi ke-i

$€$ it $=$ Komponene error pada unit observasi ke-i dan waktu ke-t. Namun untuk menganalisis dengan metode efek random ini ada satu syarat yaitu objek data silang harus lebih besar dari pada banyaknya koefisien.

\section{b. Pengujian Model}

1) Uji Chow

Rumus

yang

digunakan dalam test ini adalah

Uji Chow $=\frac{N-1}{N T-N-K}$

Dimana :

$\mathrm{N} \quad=$ Jumlah data cross section

$\mathrm{T}=$ Jumlah data

time series

$\mathrm{K}=$ Jumlah variabel penjelas

Pengujian chow dilakukan dengan hipotesis sebagai berikut :

$H_{0} \quad=\quad$ Model menggunakan pendekatan common effect

$H_{1}=$ Model menggunakan pendekatan fixed effect 
JRNAL ПMПAH

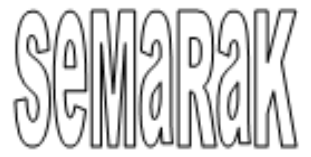

P-ISSN 2615-6849, E-ISSN 2622-3686

Jurnal Semarak,Vol.4,No.1,Februari 2021, Hal (80-95)

@Prodi Manajemen Fakultas Ekonomi Universitas Pamulang
Pengujian ini mengikuti distribusi $\mathrm{F}$ statistik, dimana jika F statistik lebih besar dari $\mathrm{F}$ tabel maka $H_{0}$ ditolak. Nilai chow menunjukan nilai $\mathrm{F}$ statistik dimana bila nilai chow yang kita dapata lebih besar dari $F$ tabel yang digunakan berarti kita menggunakan model fixed effect atau kita dapat melihat kepada nilai probabilitas cross section dan chi square, dengan ketentuan :

a) Jika probabilitas < 0,05 berarti $H_{0}$ ditolak, dan menggunakan $H_{1}$

b) Jika probabilitas > 0,05 berarti $H_{0}$ diterima

2) Uji Haussman

Uji haussman dilakukan dengan hipotesis sebagai berikut :

$H_{0}=$ Random effect Model yang paling tepat $H_{1}=$ Fixed Efect Model yang paling tepat

Statistik uji haussman ini mengikuti distribusi statistik Chi Square dengan degree of freedom sebanyak $\mathrm{k}$, dimana $\mathrm{k}$ adalah jumlah variable independen. Jika nilai statistik haussman lebih besar dari nilai kritisnya makan $H_{0}$ ditolak dan model yang tepat adalah model fixed effect, sedangkan sebaliknya bila nilai statistik hausmaan lebih kecil dari nilai kritisnya maka model yang tepat adalah model random effect, atau dapat melihat kepada nilai probabilitas cross section random, dengan ketentuan sebagai berikut :

a) Jika probabilitas $<0,05$, maka tolak $H_{0}$ dan terima $H_{1}$

b) Jika probabilitas $>0,05$, maka terima $H_{0}$ dan terima $H_{1}$.

3) Uji Langrangge Multiplier (LM)

Uji Langrangge Multiplier (LM) memakai data residual dari variable dengan cara menghitung nilai LM hitung menggunakan persamaan.

$$
\begin{aligned}
& L M_{\text {hitung }}=\frac{n T}{2(T-1)} \quad \mathrm{x} \\
& \frac{T^{2} \Sigma e^{2}}{\Sigma e^{2}}-1
\end{aligned}
$$

Dimana :

$\mathrm{N} \quad=$ Jumlah perusahaan

$\mathrm{T} \quad=\quad$ Jumlah $\Sigma e^{2} \quad=$ Jumlah ratarata residual

$\Sigma e^{2}=$ Jumlah residual kuadrat 


$\begin{aligned} & \text { hitung Nilai } \\ & \text { dibandingkan }\end{aligned} \begin{array}{r}\text { LM- } \\ \text { akan } \\ \text { dengan } \\ \text { Chi Square } \\ \text { tengan } \\ \text { derajat }\end{array}$
$\begin{aligned} & \text { kebebasan (degree of } \\ & \text { freedom) sebanyak } \\ & \text { jumlah variable }\end{aligned}$
$\begin{aligned} & \text { independen (bebas) dan } \\ & \text { alpha atau tingkat }\end{aligned}$
$\begin{aligned} & \text { signifikan sebesar 5\%. } \\ & \text { apabila nilai LM-hitung }\end{aligned}$
$>\quad$ Chi Square table
maka model yang
dipilih adalah random
effect. Apabila nilai
LM-hitung < Chi
Square table maka
model yang dipilih
adalah common effect.

c. Uji Asumsi Klasik

Uji asumsi klassik yang digunakan untuk mengetahui ketepatan data. Dalam penelitian ini uji ausmsi klasik yang digunakan adalah uji multikolinieritas, uji autokorelasi, uji heteroskedastisitas, dan uji normalitas.

\section{Uji Hipotesis}

a. Pengujian hipotesis secara parsial (uji t)

Hubungan variabel independen secara parsial dengan variabel dependen akan diuji dengan uji $t$ dengan membandingkan $t_{\text {tabel }}$ dengan $t_{\text {hitung. Adapun rumus }}$ yang digunakan dalam uji hipotesisini adalah :

$t_{1}=\frac{R \sqrt{n-2}}{\sqrt{\left(1-R^{2}\right)}}$
Keterangan :

$\mathrm{t}=$ probabilitas

$\mathrm{r}=$ koefisien korelasi

$\mathrm{n}=$ jumlah sampel

Dengan uji searah rumus

diatas, agar dapat ditarik

kesimpulan dan hipotsis maka hasil perhitungan statistic uji $\mathrm{t}$ $\left(t_{\text {hitung }}\right)$ dengan tingkat signifikasi 0,05 (5\%) dan derajat bebas n-2. Adapun kriteria penolakan dan penerimaan hipotesis $H_{0}$ adalah sebagai berikut :

1) Jika $t_{\text {hitung }}>t_{\text {tabel }}$ maka $H_{0}$ ditolak dan $H_{1}$ diterima (berpengaruh)

Jika $t_{\text {hitung }}<t_{\text {tabel }}$ maka $H_{0}$ diterima dan $H_{1}$ ditolak (tidak berpengaruh)

Kesimpulan diterima tidaknya hipotesis setelah di bandingkan $t_{\text {hitung }}$ dengan $t_{\text {tabel dengan hipotesis }}$ sebagai berikut :

(a) Variabel $X_{1}$ (arus kas)

$H_{0}: \rho_{1}=0$

Arus kas tidak berpengaruh positif dan signifikan terhadap laba $H_{1}: \rho_{1} \neq 0$

Arus kas berpengaruh positif dan signifikan terhadap laba.

(b) Variabel $X_{2}$ (modal kerja bersih)

$H_{0}: \rho_{2}=0$

Modal kerja bersih tidak berpengaruh positif dan signifikan terhadap laba $H_{1}: \rho_{2} \neq 0$

Modal kerja bersih berpengaruh positif dan signifikan terhadap laba. 
JRNAL ПMПAH

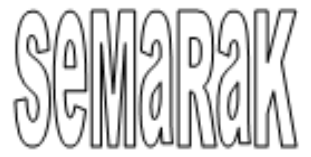

P-ISSN 2615-6849, E-ISSN 2622-3686

Jurnal Semarak,Vol.4,No.1,Februari 2021, Hal (80-95)

@Prodi Manajemen Fakultas Ekonomi Universitas Pamulang (c) Variabel $X_{3} \quad$ (hutang jangka pendek)

$H_{0}: \rho_{3}=0$

Hutang jangka pendek tidak berpengaruh positif dan signifikan terhadap laba

$H_{1}: \rho_{3} \neq 0$

Hutang jangka pendek berpengaruh positif dan signifikan terhadap laba.

(d) Variabel Y (laba)

$H_{0}: \rho_{4}=0$

Laba tidak berpengaruh positif dan signifikan terhadap pembagian deviden

$H_{1}: \rho_{4} \neq 0$

Laba berpengaruh positif dan signifikan terhadap pembagian deviden.

b. Pengujian Hipotesis Secara Simultan (Uji F)

Uji F digunakan untuk mengetahui ada atau tidaknya pengaruh bersanma (simultan) arus kas, modal kerja bersih, hutang jangka pendek terhadap laba.

Menurut Sugiyono (2014:253), uji F digunakan untuk mengetahui pengaruh secara bersama-sama variabel independen terhadap variabel dependen. Uji menguji adanya hubungana antara variabel bebas secara simultan berdampak terhadap variabel Y dilakukan perhitungan dengan rumus sebagai berikut :
$F_{\text {hitung }}$
$=\frac{R^{2} / k}{\left(1-R^{2}\right) /(n-k-1)}$

Sumber : Sugiyono (2014:253)

Dimana :

$R^{2}=$ Koefisien korelasi ganda

$k=\quad$ Jumlah variabel

independen

$n=$ Jumlah data

Untuk mengetahui sebuah hipotesis secara simultan diterima atau ditolak yaitu dengan membandingkan antara $F_{\text {hitung }}$ dengan $F_{\text {tabel }}$ atau nilai probabilitas dengan Sig. 0,05. Adapun kriteria penolakan dan penerimaan hipotesis $H_{0}$ adalah sebagai berikut :

1) Berdasarkan perbandingan tstatistik dengan $t$ tabel

(a) Jika $F_{\text {hitung }}>F_{\text {tabel }}$ maka $H_{0}$ diterima dan $H_{1}$ ditolak

(b) Jika $F_{\text {hitung }}<F_{\text {tabel }}$ maka $H_{0}$ ditolak dan $H_{1}$ diterima

2) Berdasarkan perbandingan probabilitas

(a) Jika Prob (F Statistic) >, maka $H_{0}$ diterima dan $H_{1}$ ditolak

(b) Jika Prob (F Statistic) <, maka $H_{0}$ ditolak dan $H_{1}$ diterima.

\section{Operasional Variabel Penelitian}

\begin{tabular}{|c|c|c|}
\hline VARIABEL & DEFINISI OPERASIONAL & $\begin{array}{c}\text { INDIKATOR } \\
\text { PENGUKURAN } \\
\end{array}$ \\
\hline $\begin{array}{c}\text { Arus Kas } \\
\left(\mathrm{X}_{1}\right)\end{array}$ & $\begin{array}{l}\text { Kas merupakan dalah satu unsur } \\
\text { modal kerja yang paling tinggi } \\
\text { tingkat likuiditasnya. }\end{array}$ & Total arus kas \\
\hline $\begin{array}{l}\text { Modal Kerja } \\
\quad\left(\mathrm{X}_{2}\right)\end{array}$ & $\begin{array}{l}\text { Modal kerja didefinisikan sebagai } \\
\text { modal yang digunakan untuk } \\
\text { membiayai operasional } \\
\text { perusahaan sehari-hari, terutama } \\
\text { yang memiliki jangka waktu } \\
\text { pendek. }\end{array}$ & $\begin{array}{l}\text { Selisih antara aktiv: } \\
\text { lancar dengan hutan } \\
\text { lancar }\end{array}$ \\
\hline $\begin{array}{c}\text { Hutang } \\
\text { Jangka } \\
\text { Pendek } \\
\left(\mathrm{X}_{3}\right)\end{array}$ & $\begin{array}{l}\text { Hutang jangka pendek adalah } \\
\text { kewajiban perusahaan kepada } \\
\text { pihak lain yang harus dipenuhi } \\
\text { dalam jangka waktu normal, } \\
\text { umumnya satu tahun atau } \\
\text { kurang, semenjak disusun, atau } \\
\text { hutang yang jatuh temponya } \\
\text { masuk siklus akuntansi yang } \\
\text { sedang berjalan. }\end{array}$ & $\begin{array}{l}\text { Semua hutang jangki } \\
\text { pendek }\end{array}$ \\
\hline
\end{tabular}


JRNAL ПMПAH Sempardad
P-ISSN 2615-6849, E-ISSN 2622-3686

Jurnal Semarak,Vol.4,No.1,Februari 2021, Hal (80-95)

@Prodi Manajemen Fakultas Ekonomi Universitas Pamulang

\section{HASII PENEIITIAN}

Hasil Uji-t dan Uji F Pengaruh Arus Kas, Modal kerja Bersih dan Hutang Jangka Pendek Terhadap Laba

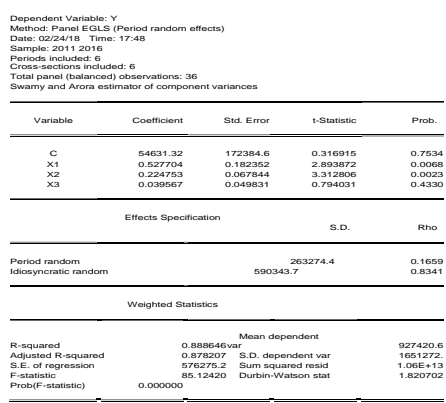

a. Pengaruh Arus Kas Terhadap Laba

Hasil pengujian analisis regresi pada tabel hasil pengujian menunjukan bahwa nilai $t_{\text {hitung }}$ arus kas secara parsial diperoleh $t_{\text {hitung }}>t_{\text {tabel }}(2.894>1.694)$, maka $H_{0}$ ditolak dan $H_{1}$ diterima sedangkan nilai probability $0.0068<0.05$ kondisi tersebut menunjukan bahwa variabel arus kas berpengaruh secara signifikan terhadap varibel laba.

b. Pengaruh Modal Kerja Bersih Terhadap Laba

Hasil pengujian analisis regresi pada tabel hasil pengujian menunjukan bahwa nilai $t_{\text {hitung }}$ modal kerja bersih secara parsial diperoleh $t_{\text {hitung }}>t_{\text {tabel }} \quad(3.313$ >1.694), maka $H_{0}$ ditolak dan $H_{1}$ diterima sedangkan nilai probability $0.0023<0.05$ kondisi tersebut menunjukan bahwa variabel modal kerja bersih berpengaruh secara signifikan terhadap varibel laba.

c. Pengaruh Hutang Jangka Pendek Terhadap Laba

Hasil pengujian analisis regresi pada tabel hasil pengujian menunjukan bahwa nilai $t_{\text {hitung }}$ hutang jangka pendek secara parsial diperoleh $t_{\text {hitung }}<t_{\text {tabel }}$ $(0.7940<1.694)$, maka $H_{0}$ diterima dan $H_{1}$ ditolak sedangkan nilai probability $0.4330>0.05$ kondisi tersebut menunjukan bahwa variabel hutang jangka pendek tidak berpengaruh secara signifikan terhadap varibel laba.

d. Pengaruh Arus Kas, Modal Kerja Bersih, dan Hutang Jangka Pendek Terhadap Laba

Berdasarkan tabel 4.12 hasil uji regresi untuk pengujian pengaruh arus kas, modal kerja bersih dan hutang jangka pendek terhadap laba secara simultan dan bersama- 
JRNAL ПMПAH

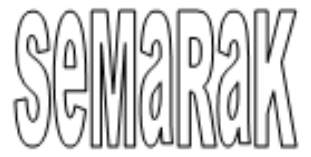

P-ISSN 2615-6849, E-ISSN 2622-3686

Jurnal Semarak,Vol.4,No.1,Februari 2021, Hal (80-95)

@Prodi Manajemen Fakultas Ekonomi Universitas Pamulang $\begin{array}{llr}\text { sama, } & \text { didapatkan } & \text { nilai } \\ F_{\text {hitung }}>F_{\text {tabel }} & (85.124> & 2.90) \\ \text { dengan nilai } & \text { probabilitas } \\ \text { (signifikansi) } & 0.000000< & 0.05\end{array}$ (signifikansi) $\quad 0.000000<0.05$. Maka $H_{0}$ ditolak dan $H_{1}$ diterima. Hal ini menunjukan bahwa arus kas, modal kerja bersih dan hutang jangka pendek secara simultan dan bersama-sama berpengaruh terhadap laba.

Berdasarkan hasil Eviews pada tabel 4.12 di atas, maka diperoleh persamaan model regresi antara variabel arus kas, modal kerja bersih, dan hutang jangka panjang terhadap variabel laba yaitu sebagai berikut:

$\mathrm{Y}=54631,32+0.527704 \mathrm{X} 1+$ 0.224753 X2 + 0.039567 X3

e. Pengaruh Laba Terhadap Pembagian Dividen

Dependent Variable: Z

Method: Panel Least Square

Date: 03/29/18 Tim

Sample: 20112016

Periods included: 6

Toss seclions included. 6

\begin{tabular}{lrlll}
\hline \hline \multicolumn{1}{c}{ Variable } & Coefficient & Std. Error & t-Statistic & Prob. \\
\hline \hline \multicolumn{1}{c}{ C } & -32910.16 & 65770.16 & -0.500381 & 0.6200 \\
Y & 0.301503 & 0.030789 & 9.792579 & 0.0000 \\
\hline \hline R-squared & 0.738249 & Mean dependent var & 381203.7 \\
Adjusted R-squared & 0.730551 & S.D. dependent var & 582246.1 \\
S.E. of regression & 302235.2 & Akaike info criterion & 28.12975 \\
Sum squared resid & $3.11 E+12$ & Schwarz criterion & 28.21772 \\
Log likelihood & -504.3355 & Hannan-Quinn criter. & 28.16046 \\
F-statistic & 95.89459 & Durbin-Watson stat & 0.732761 \\
Prob(F-statistic) & 0.000000 & & \\
\hline \hline
\end{tabular}

Sumber : Hasil Penelitian diolah, 2018

Berdasarkan tabel hasil uji $\mathrm{t}$ pengaruh laba terhadap pembagian dividen diketahui hasil pengujian analisis regresi menunjukan bahwa nilai $t_{\text {hitung }}$ laba secara parsial diperoleh $t_{\text {hitung }}>t_{\text {tabel }} \quad(9.793>1.694)$. Maka $H_{0}$ ditolak dan $H_{1}$ diterima. Hal tersebut menunjukan bahwa Variabel laba secara parsial berpengaruh signifikan terhadap variabel pembagian dividen.

\section{f. Koefisien Determinasi Tabel Hasil Pengujian Koefisien Determinas}

\begin{tabular}{|c|c|c|c|c|}
\hline $\begin{array}{l}\text { Dependent Variable: } \\
\text { Method: Panel EGLS } \\
\text { Date: 02/24/18 Time } \\
\text { Sample: } 20112016 \\
\text { Periods included: } 6 \\
\text { Cross-sections includ } \\
\text { Total panel (balanced } \\
\text { Swamy and Arora es }\end{array}$ & $\begin{array}{l}\text { d random ef } \\
8\end{array}$ & ects) & & \\
\hline Variable & Coefficient & Std. Error & $\mathrm{t}$-Statistic & Prob. \\
\hline C & 54631.32 & 172384.6 & 0.316915 & 0.7534 \\
\hline $\mathrm{X} 1$ & 0.527704 & 0.182352 & 2.893872 & 0.0068 \\
\hline $\mathrm{x} 2$ & 0.224753 & 0.067844 & 3.312806 & 0.0023 \\
\hline $\mathrm{X} 3$ & 0.039567 & 0.049831 & 0.794031 & 0.4330 \\
\hline & Effects Sp & cification & & \\
\hline & & & S.D. & Rho \\
\hline Period random & & & 263274.4 & 0.1659 \\
\hline Idiosyncratic random & & & 590343.7 & 0.8341 \\
\hline & Weighted & Statistics & & \\
\hline R-squared & 0.888646 & Mean depend & t var & 927420.6 \\
\hline Adjusted R-squared & $\begin{array}{l}.000040 \\
0.878207\end{array}$ & S.D. depende & & 1651272. \\
\hline S.E. of regression & 576275.2 & Sum squared & & $1.06 \mathrm{E}+13$ \\
\hline F-statistic & 85.12420 & Durbin-Watso & & 1.820702 \\
\hline Prob(F-statistic) & 0.000000 & & & \\
\hline
\end{tabular}

Sumber : Hasil Penelitian diolah, 2018

Berdasarkan tabel tersebut besarnya angka Adjusted R-Squared $\left(\mathrm{R}^{2}\right)$ adalah sebesar 0.888646hal ini menunjukkan bahwa persentase sumbangan pengaruh variabel independen terhadap variabel dependen adalah sebesar $88.86 \%$ terhadap variabel dependennya. Sedangkan sisanya $46.80 \%$ dipengaruhi faktor lain di luar model regresi tersebut.

\section{KESIMPULAN DAN SARAN}

\section{A. KESIMPULAN}

Berdasarkan hasil analisis data penelitian dan pembahasan yang telah dilakukan dalam penelitian mengenai "Analisis Pengaruh ArusKas, Modal Kerja Bersih dan Hutang Jangka Pendek terhadap Laba dan Dampaknya Terhadap Pembagian 
JRNAL ПMПAH Samlandid
P-ISSN 2615-6849, E-ISSN 2622-3686

Jurnal Semarak,Vol.4,No.1,Februari 2021, Hal (80-95)

@Prodi Manajemen Fakultas Ekonomi Universitas Pamulang
Dividen. Studi Pada Perusahaan Industri Makanan dan Minuman yang Terdaftar di Bursa Efek Indonesia Periode Tahun 20112016". Setelah melalui tahap pengumpulan data, pengolahan data, analisis data dan yang terakhir interpretasi hasil analisis data maka dihasilkan kesimpulan sebagai berikut:

1. Arus kas $\left(X_{1}\right)$ berpengaruh secara signifikan terhadap laba $(\mathrm{Y})$

2. Modal kerja bersih $\left(X_{2}\right)$ berpengaruh secara signifikan terhadap laba $(Y)$

3. Hutang jangka pendek $\left(X_{3}\right)$ tidak berpengaruh secara signifikan terhadap laba (Y)

4. Arus kas $\left(X_{1}\right)$, modal kerja bersih $\left(X_{2}\right)$, hutang jangka pendek $\left(X_{3}\right)$ secara simultan berpengaruh secara signifikan terhadap laba (Y) sebesar 88.86\%, sedangkan $11,14 \%$ dipengaruhi oleh variabel lain.

5. Laba (Y) berpengaruh secara signifikan terhadap pembagian dividen (Z)

\section{B. SARAN}

Berdasarkan hasil penelitian yang telah dilakukan dan kesimpulan yang diperoleh di atas, maka dengan segala keterbatasan dan kesempatan yang dimiliki penulis akan mencoba untuk memberikan saran yang bermanfaat bagi pembaca khususnya bagi perusahaanya itu antara lain:

1. Peneliti selanjutnya diharapkan dapat menambah variabel-variabel atau faktor-faktor lain yang mempengaruhi variable dependen maupun variabel moderator di luar dari variable arus kas, modal kerja bersih, dan hutang jangka pendek

2. Dalam pengelolaan modal kerja memerlukan perhatian khusus. Perusahaan juga harus menjaga profitabilitasnya, agar jika terjadi krisis, tidak berimbas pada perusahaan sehingga perusahaan tetap mampu memperoleh laba dalam menjalankan usahanya.

3. Dalam melaksanakan pemenuhan kebutuhan dana, perusahaan harus mencari alternative sumber dana untuk dianalisa kemudian dengana nalisa tersebut diambil keputusan alternative sumber dana yang akan dipilih,

4. Penelitian ini dapat dijadikan sebagai bahan referensi untuk penelitian berikutnya agar dapat dikembangkan menjadi lebih baik lagi.

\section{DAFTAR PUSTAKA}

Abidin, Zainal dan Dewi, "Pengaruh Modal Kerja Bersih Terhadap Laba Bersih Pada PT. Soelina Interkarya Processing", Unpam, 2014.

Bungin, Burhan, "Metodologi Penelitian Kuantitatif; Komunikasi Ekonomi, dan Kebijakan Publik Serta Ilmu-ilmu Sosial Lainnya", Edisi 1 Cetakan 4, Kencana, Jakarta, 2009.

Enterprise, Jubilee, “Java Untuk Pemula”, PT. Elex Media Komputindo, Jakarta, 2014.

Fahmi, Irham, "Analisa Laporan Keuangan”, CV. Alfabeta, Bandung, 2012.

Fami, Irham, "Analisis Laporan Keuangan", Alfabeta, Bandung, 2013.

Gendro dan Hadri, "Manajemen Keuangan Lanjutan", Cetakan 1, UPP STIM YKPM, Yogyakarta, 2017 
JRNAL ПMПAH

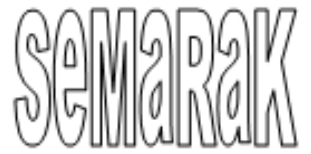

P-ISSN 2615-6849, E-ISSN 2622-3686

Jurnal Semarak,Vol.4,No.1,Februari 2021, Hal (80-95)

@Prodi Manajemen Fakultas Ekonomi Universitas Pamulang
Ghozali, Imam, "Aplikasi Analisis Multivariete", Edisi 8, UNDIP, Semarang, 2016.

Gujarati, "Dasar-dasar Ekonometrika", Salemba Empat, Jakarta, 2014.

Hery, "Cara Cepat dan Mudah Memahami Pengantar Manajemen", Cetakan 1, Gava Media, Yogyakarta, 2017.

Husnan, Suad, “Manajemen Keuangan”, Edisi 2 Cetakan ke 5, Universitas Terbuka, Jakarta, 2011.

I Gede dan Neneng, " Kajian Analisis Regresi Dengan Data Panel", Universitas Negeri Yogyakarta, 2009. (Jurnal)

Ikatan Akuntansi Indonesia, "Standar Akuntansi Keuangan”, Salemba Empat, Jakarta, 2007.

James, " Statistik Untuk Bisnis Dan Ekonomi”, Erlangga, Jakarta, 2011.

Jumingan, “Analisis Laporan Keuangan”, Bumi Aksara, Jakarta, 2012.

Jumingan, "Analisis Laporan Keuangan", Cetakan Ke Empat, PT. Bumi Aksara, Jakarta, 2011.

Kasmir, "Pengantar Manajemen Keuangan”, Edisi 1 Cetakan Ke 2, Kencana Prenada Media Group, Jakarta, 2010.

Kieso dkk, "Akuntansi Intermediate", Edisi Kedua Belas, Erlangga, Jakarta, 2008.

Kuswandi, "memahami rasio keuangan orang awam", PT. Elex Media Komputindo, Jakarta, 2006.
Manurung, "Cara Menilai Perusahaan", PT. Elex Media Komputindo, Jakarta, 2014.

Mardiyanto, Handoyo, "Intisari Manajemen Keuangan”, Grasindo, Jakarta, 2009.

Matono dan Agus, "Manajemen Keuangan", Edisi 3, Ekonisia, Yogyakarta, 2010.

Muawanah, Umi, "Konsep Daasar Akuntasni Dan Pelaporan Keuangan”, 2008.

Mustafa, "Manajemen Keuangan", CV. Andi Offset, Yogyakarta, 2017.

Nachrowi, "Ekonometrika Untuk Analisis Ekonomi Dan Keuangan", Cetakan Ke 1, Lembaga Penerbit FE UI, Jakarta, 2016.

Nana dan Denny "Analisis Pengaruh Arus Kas Bersih Dan Laba Terhadap Saham Syariah", Jurnal Akuntansi, Vol. 1.3 No. 1, 2016

O Gill, James dan Moira Chatton, "Memahami Laporan Keuangan", PPM, Jakarta, 2010

Purnomo, S., \& Pasaribu, V. L. D. (2019).

Pergerakan Harga Saham Pt Adaro Energy Tbk (Adro) Pada Pengumuman Dividen Interim Tahun Buku 2018. Jurnal Ekonomi Efektif, 2(1).

Purwanti, Sri dkk, "Pengaruh Laba Akuntansi Dan Arus Kas Terhadap Return Saham Perushaan Yang Listing Di BEI', Jurnal Akuntasi dan Pajak, UNIBA, Surakarta, 2015.

Raharjo dan hendra, "Manajemen Keuangan Dan Akuntasi", Salemba Empat, Jakarta, 2009. 
JRNAL ПMПAH Semplardid
P-ISSN 2615-6849, E-ISSN 2622-3686

Jurnal Semarak,Vol.4,No.1,Februari 2021, Hal (80-95)

@Prodi Manajemen Fakultas Ekonomi Universitas Pamulang
Riduwan, "Metode dan Teknik Cara Menyusun Tesis", Cetakan ke Sepuluh, Alfabeta, Bandung, 2014.

Sugiyono, "Metode Penelitian Kuantitatif, kualitatif $R \& D ", \quad$ cv. Alfabeta, Bandung, 2014.

Sugiyono, "Metode Penelitian Kuantitatif, Kualitatif, dan $R \& D$ ”, Cetakan Ke 16, CV. Alfabeta, Bandung, 2012.

Susanto, Agus "Pengaruh hutang jangka pendek, hutang jangka panjang dan modal kerja bersih dan dampaknya terhadap nilai perusahaan pada industri rokok yang terdaftar di BEI", Tesis Universitas Pamulang, 2017

Weston, J Fred dan Copeland E. Thomas, "Manajemen Keuangan", Edisi Sembilan, Binarupa Aksara, Jakarta, 2009.

Winarno, Wahyu, “Analisis Ekonometrika dan Statistika dengan Eviews",UPP STIM YKPN, Yoyakarta, 2011.

Yuni, "Pengaruh Ukuran Perusahaan, Struktur Hutang, Dan Umur Perusahaan Terhadap Profitabilitas Pada Perusahaan Food And Beverages Di $B E \Gamma^{\prime}$, Jurnal Penelitian Ekonomi Dan Akuntansi, Univeritas Islam Lamongan, 2006.

Jurnal Ilmiah manajemen dan Akuntansi (ISSN) Vo. 2 No. 2 Tahun 2015

Jurnal Ilmiah Prodi Manajemen Universitas Pamulang Vol. 2 No. 1 Tahun 2014

Jurnal Ilmu dan Riset Manajemen Vol. 1 No. 2 Tahun 2012 http://cahyanidewi.blogspot.com/2013/10/man ajermen-keuangan-fungsi dan tinjauan.html

http://junaidicaniago.wordpress.com/2010

http://www.e-

akuntansi.com/2014/11/mengnaisisaktivitas-bisnis.html?m=1

http://www.scribd.com.mobile/document/1147 58886/pengaruh-llaba-bersih-terhadappembagian-dividen-kas-perusahaantambang-batu-bara-pt-bukit-asam

https://ejournal.stiesia.ac.id/jirm/article/view/3 1

https://ejournal.unsrat.ac.id/index.php/emba/art icle/view/15454 
JRNAL ПMМAH

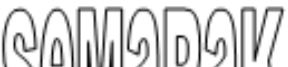

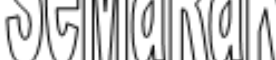

P-ISSN 2615-6849 , E-ISSN 2622-3686

Jurnal Semarak,Vol.4,No.1,Februari 2021, Hal (80-95)

@Prodi Manajemen Fakultas Ekonomi Universitas Pamulang 